\section{Long-term effect of xylitol chewing gum on dental caries}

Isokangas P, Tiekso J, Alanen P, Mäkinen KK: Long-term effect of xylitol chewing gum on dental caries. Community Dent Oral Epidemiol 1989; 17: 200-3.

Abstract - About $85 \%(n=269)$ of the subjects who participated in the Ylivieska follow-up studies on the effect of xylitol chewing gum on dental caries during 1982-84 or 1982-85 were re-examined in 1987 for the analysis of possible long-term preventive effects. Further caries reduction was found 2 or 3 yr after the discontinuation of the use of xylitol. The effect was especially marked in girls; the reduction in caries increment in the post-use years was $60 \%$ for the 2 -yr users, suggesting that more pronounced caries reduction was associated with the most regular use of xylitol. In teeth erupting during the first year of the use of xylitol gum the long-term preventive effect was greater than in other teeth. Several explanations are suggested: lasting effect of the microbiological changes in the mouth, bacterial colonization on newly erupted teeth by organisms other than $S$. mutans, and/or thorough maturation of the teeth under favorable physico-chemical circumstances. The results suggest that the value of xylitol in caries prevention depends on the timing of the treatment in relation to the development of the dentition.
Pauli Isokangas' ${ }^{1}$, Jaakko Tiekso², Pentti Alanen ${ }^{2}$ and Kauko K. Mäkinen ${ }^{3}$ 'Public Health Center, Ylivieska, ${ }^{2}$ Institute of Dentistry, University of Turku, Finland; ${ }^{3}$ School of Dentistry, The University of Michigan, Ann Arbor, Michigan, USA

Key words: cost-effectiveness analysis; dental caries; long-term effects; prevention; xylitol

Dr. Pauli Isokangas, Ylivieska Health Care Center, SF-84100 Ylivieska, Finland

Accepted for publication 3 February 1989
The studies available on the long-term effect of caries preventive agents or procedures are few, and have given equivocal results (1-7). However, for the assessment of the value of a preventive program it is important to know whether the effect on dental caries is temporary or lasting and information on the possible long-term effects is also needed for costeffectiveness analyses (8).

Two longitudinal field studies, one lasting $2 \mathrm{yr}$ and the other $3 \mathrm{yr}$, were carried out in Ylivieska, Finland, in 1982-85, with subjects initially aged 11-12 yr. The results showed that regular use of a chewing gum containing xylitol further increased the efficacy of the existing preventive measures, which were mainly based on fluorides and which are regularly applied in Finnish Health Centers $(9,10)$. The results were in line with other studies on xylitol (11-15; for a review, see 16) and indicate the existence of a cariostatic mechanism induced by peroral xylitol $(11,17)$. In no previous studies, however, has the possible longterm clinical effect of xylitol been analyzed.

The aim of the present study was to analyze the increment of dental caries during three post-experimental years (1984-87) in subjects who used xylitol chewing gum for $2 \mathrm{yr}$, and during two post-use years (1985-87) in high-risk subjects who used xylitol for $3 \mathrm{yr}$.

\section{Subjects and methods}

The original Ylivieska xylitol study was a field trial, in which the experimental group and control group consisted of parallel classes at school. The detailed arrangement of the study has been published earlier $(9,10)$. The original 2-yr study consisted of 172 children initially aged 11-12 yr (mean age $11.5 \mathrm{yr}$ ) who used xylitol chewing gum two to three times per day, and 152 children of the same age (mean $11.5 \mathrm{yr}$ ) who formed the control (no-gum) group. All the children received the same basic fluoride prevention. On the basis of the total caries experience recorded at the beginning of the study in 1982, 30 of the original 172 children were classified as high-risk subjects for dental caries, and they continued the daily use of xylitol chewing gum for one more year. Using similar criteria, 36 children in the control group were chosen as controls for the 3-yr study. The criteria for allocating subjects to high-risk groups and the evaluation of the method used have been published elsewhere (9).

A total of 147 children $(85 \%)$ of the original xylitol group and 122 children $(80 \%)$ of the original control group were clinically re-examined in 1987, i.e. 3 yr after the discontinuation of the daily use of xylitol gum in the main experimental group (2 $\mathrm{yr}$ after discontinuation in the high-risk groups). A blind study design was applied, and the re-examinations were carried out by two dentists who had participated in the original studies (9). Of the re-examined children 120 had used xylitol chewing gum for 2 yr (1982-84) and 27 belonged to the high-risk subjects who had used xylitol for 3 yr (1982-85), while in the re-examined control group, 31 children had originally (1982) been classified as high-risk subjects (Fig. 1).

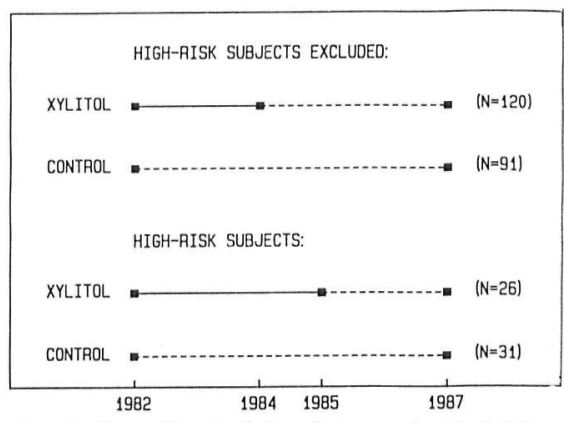

Fig. 1. Overall schedule of the study. Solid line refers to the use of xylitol chewing gum in the original 2- and 3-yr trials. 
The criteria for dental decay were the same as those used during the original studies (9). However, enamel caries $\left(D_{1}\right)$ was not registered for the present analysis. Detailed information on the criteria, which are in accordance with WHO guidelines (18), has been given by IsoKANGAS (9). For comparison in the present study, the results of the original 2and 3-yr trials were recalculated for the participants in the re-examination according to the design presented in Fig. 1. The use of xylitol gum and other sweets during the intervening years 1984-87 (1985-87 for the high-risk subjects) in both the xylitol and control groups was checked by a questionnaire.

\section{Results \\ Subjects who used xylitol chewing gum for 2 yr (1982-84)}

In boys, the reduction in dental caries, measured as $\triangle D_{2}$ MFS, was $33 \%$ in the xylitol (X) group during the original 2yr study in $1982-84$, and $31 \%$ during the years $1984-87$ as compared to the control (C) group. In the X-group girls, the corresponding figures were $46 \%$ and $60 \%$ (Fig. 2). The caries increment values for 1984-87 were 2.1 in the X-group boys (95\% confidence limits 1.2, 3.0), 3.2 in the C-group boys $(1.8,4.6), 1.0$ in the $\mathrm{X}$ group girls $(0.6,1.4)$, and 2.5 in the $\mathrm{C}$ group girls $(1.3,3.7)$, respectively. In view of the differences in total caries experience at the baseline examination, the caries increment was also analyzed after stratification by baseline DMF. In those for whom baseline $\mathrm{DMF}=0$, xylitol users did not differ from control group children with respect to $2-\mathrm{yr}$ or 5 -yr caries increment. In the two other strata, however, both for boys and girls, the reduc-

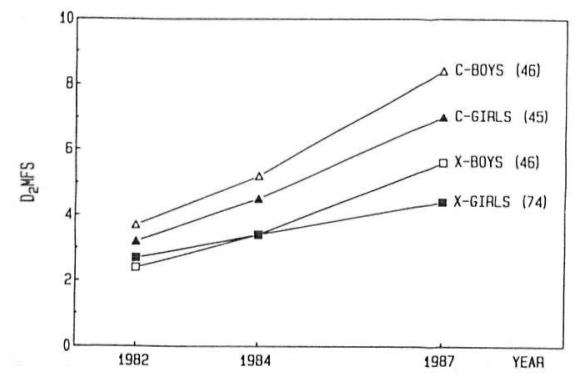

Fig. 2. Dentinal caries increment during 1982-84 and 1984-87 in all teeth in subjects who used xylitol gum for $2 \mathrm{yr}$ in 1982-84 (X), and in the control subjects (C), boys and girls separately.

Table 1. Caries increment ( $\left.\triangle \mathrm{D}_{2} \mathrm{MFS}\right)$ during experimental and post-experimental years in xylitol $(\mathrm{X})$ and control (C) groups expressed by baseline DMF and by sex, and caries reduction in the $\mathrm{X}$-subgroups as compared to the corresponding C-subgroups

\begin{tabular}{|c|c|c|c|c|c|c|c|c|}
\hline \multirow{2}{*}{$\begin{array}{l}\text { Baseline } \\
\text { DMF }\end{array}$} & \multirow[b]{2}{*}{ Subgroup } & \multirow[b]{2}{*}{$n$} & \multicolumn{3}{|c|}{$\triangle \mathrm{D}_{2} \mathrm{MFS}_{82-84}$} & \multicolumn{3}{|c|}{$\triangle \mathrm{D}_{2} \mathrm{MFS}_{8487}$} \\
\hline & & & Mean & $\mathrm{SD}$ & Reduction \% & Mean & SD & Reduction $\%$ \\
\hline \multirow[t]{4}{*}{0} & X-boys & 16 & 0.7 & 2.0 & \multirow[t]{2}{*}{13} & 2.4 & 3.9 & \multirow[t]{2}{*}{-20} \\
\hline & C-boys & 10 & 0.8 & 1.6 & & 2.0 & 2.2 & \\
\hline & X-girls & 23 & 0.4 & 0.6 & \multirow[t]{2}{*}{20} & 1.0 & 1.5 & \multirow[t]{2}{*}{0} \\
\hline & C-girls & 8 & 0.5 & 0.8 & & 1.0 & 1.1 & \\
\hline \multirow[t]{4}{*}{$1-2$} & X-boys & 17 & 1.1 & 1.6 & \multirow[t]{4}{*}{27} & 2.1 & 2.9 & \multirow[t]{4}{*}{51} \\
\hline & C-boys & 15 & 1.5 & 2.0 & & 4.3 & 4.7 & \\
\hline & $X$-girls & 26 & 0.7 & 1.4 & & 0.6 & 1.0 & \\
\hline & C-girls & 17 & 1.2 & 1.3 & & 1.6 & 1.8 & \\
\hline \multirow[t]{4}{*}{$3-$} & X-boys & 13 & 1.5 & 2.3 & \multirow[t]{4}{*}{21} & 1.9 & 2.2 & \multirow[t]{2}{*}{37} \\
\hline & C-boys & 21 & 1.9 & 2.0 & & 3.0 & 5.3 & \\
\hline & $\mathrm{X}$-girls & 25 & 1.0 & 2.3 & & 1.4 & 2.6 & \multirow[t]{2}{*}{64} \\
\hline & $C$-girls & 20 & 1.8 & 2.1 & & 3.9 & 5.5 & \\
\hline
\end{tabular}

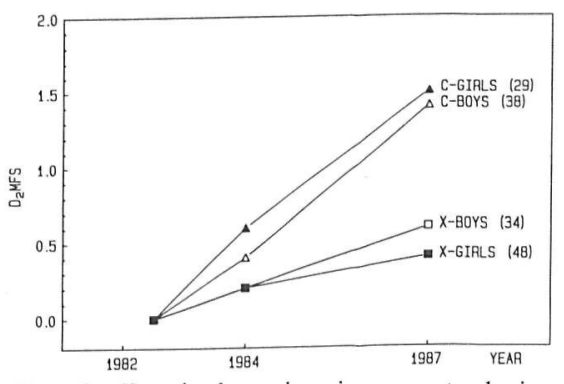

Fig. 3. Dentinal caries increment during 1982-84 and 1984-87 in those teeth that erupted during the first year of the use of xylitol gum in the xylitol group (X), and in the control group (C), boys and girls separately.

tion was greater during the post-experiment years 1984-87 than during the actual field trial in 1982-84 (Table 1).

In those teeth that erupted during the first year of using xylitol, the long-term effect was greater than in teeth overall: the reduction was $50 \%$ for boys during the original study, and $60 \%$ during the post-use years of 1984-87. In girls the corresponding figures were $67 \%$ and $79 \%$ (Fig. 3). The increment values for erupted teeth were 0.4 for X-boys $(95 \%$ confidence limits $0.1,0.7), 1.0$ for C-boys $(0.4,1.6), 0.2$ for $\mathrm{X}$-girls $(0.1,0.3)$, and 1.0 for $\mathrm{C}$-girls $(0.4,1.6)$.

High-risk subjects who used xylitol chewing gum for 3 yr (1982-85)

The mean caries increment for the highrisk children during the experimental period 1982-85 was 2.9 in the xylitol group and 6.6 in the control group, representing a reduction of $55 \%$ in the Xgroup as compared to the C-group. During the follow-up period the mean increment was 1.4 in the X-group and 2.4 in the $\mathrm{C}$-group, representing a corresponding reduction of $39 \%$ (Table 2). In those teeth which erupted during the first year of using xylitol, the reduction was $76 \%$ in the original study, and $14 \%$ in the follow-up years 1985-87 (Table 2).

\section{Use of xylitol chewing gum}

Distribution of xylitol chewing gum to the children ended in 1984 (1985 to high-

Table 2. Mean caries increment with $95 \%$ confidence limits in the high-risk subjects in the xylitol and the control group during the experimental years 1982-85 and follow-up years 1985-87, separately for all teeth and for teeth erupting during the first experimental year

\begin{tabular}{lccccc}
\hline & \multicolumn{3}{c}{$\begin{array}{c}\triangle \mathrm{D}_{2} \mathrm{MFS}_{82-85} \\
95 \% \\
\text { confidence limits }\end{array}$} & $\bar{x}$ & $\begin{array}{c}\triangle \mathrm{D}_{2} \mathrm{MFS}_{85-87} \\
95 \% \\
\text { confidence limits }\end{array}$ \\
\hline $\begin{array}{l}\text { All teeth } \\
\quad \text { Xylitol }\end{array}$ & 26 & 2.9 & $1.8,4.0$ & 1.4 & $0.3,2.5$ \\
$\quad$ Control & 31 & 6.6 & $4.9,8.3$ & 2.4 & $0.4,4.4$ \\
Erupted teeth & 12 & 0.4 & $-0.2,1.0$ & & \\
$\quad$ Xylitol & 16 & 1.7 & $0.9,2.5$ & 0.6 & $0.0,1.2$ \\
$\quad$ Control & & & & 0.8 & $-0.3,1.9$ \\
\hline
\end{tabular}


risk subjects). The questionnaire survey revealed that 10 children in the xylitol group had daily used commercially available xylitol gums during post-experimental years. One of these children belonged to the high-risk group. In the control group, 10 children had also used xylitol chewing gum regularly after the termination of the original 2- or 3-yr studies. Three of these children were classified as high-risk subjects.

\section{Discussion}

The participation of the children in the re-examination can be regarded as satisfactory. The essential reason for losing $17 \%$ of the subjects was their moving from the community. Because of the loss, the results from the 2- and 3-yr studies were recalculated for the re-examined subjects; but since the caries increment values were practically identical with the original ones (9), we consider that the dropouts did not affect the comparisons.

Inter- and intra-examiner analyses for caries registration were carried out in the original studies (9). Due to practical reasons such as difficulties in contacting the subjects, it was not possible to arrange a new reproducibility analysis for the observations in the present study. However, the two examiners involved were experienced clinicians who had showed good repeatability during the original study (9). In view of this and of the blind study design, there is no reason to suspect biased observations.

The 2- and 3-yr Ylivieska xylitol studies showed that only regular use of xylitol chewing gum, i.e. two to three times per day, was associated with a significant reduction in caries increment. Since only a few children had used xylitol regularly on this scale after the experimental period, voluntary use seems to have no or only very limited effect on the long-term results in the main part of the material. However, in high-risk subjects the postexperimental use of xylitol may have confounded the analyses. This is due to the small number of high-risk children in the re-examination, especially with teeth erupting during the use of xylitol.

Earlier long-term studies on caries prevention have not separately analyzed those teeth that erupted during the treatment period. It is possible that the equivocal results obtained in those studies are partly associated with that fact. Our find- ings indicate that the additional degree of prevention, which was found in all teeth during the post-use years, was even better in teeth erupting during the active period of treatment with xylitol. This observation suggests that the timing of preventive measures (as well as the timing of studies on caries prevention) in relation to the development of the dentition may materially affect the results.

Several possible explanations can be suggested for the fact that an additional degree of prevention was found without any prolonged treatment. In the first place, even discounting biological explanations for the observation, the xylitol group may have showed less caries for "technical reasons". By this we mean that there may have been fewer active subclinical caries lesions which could have grown rapidly to clinically detectable dentinal caries in the xylitol group than in the control group. Especially in the high-risk groups, where the post-experimental follow-up period was only $2 \mathrm{yr}$, this possible technical effect should be taken into account.

In our view, the more probable explanation for the increased difference between the xylitol and control groups during the post-use years is the occurrence of microbiological changes in the mouth and/or the maturation of the erupting teeth under favorable physico-chemical conditions. The microbiological followup of the Ylivieska subjects demonstrated that the reduction in caries incidence during the use of xylitol chewing gum was related to a selective inhibition of Streptococcus mutans (17). It is, therefore, possible that those teeth that erupted during xylitol treatment were permanently colonized by bacteria other than S. mutans, thus showing high resistance against caries even without prolonged use of xylitol. On the other hand, it has been suggested that a tooth is most sus- ceptible to caries attack immediately after eruption (19). Because of this, and as a result of successful maturation, the teeth that erupted during the active use of xylitol may be better protected against caries than the teeth in control group children. A study by Alanen et al. (5) demonstrated that teeth that erupted during the Second World War, when the use of sugar was strongly reduced, had after an elapse of $40 \mathrm{yr}$ experienced less caries than teeth erupting before or after the war. Our present results do not make it possible to evaluate the relative weight of these two explanations.

There was also no significant difference in caries increment between those subjects in the xylitol and the control groups who did not have decayed, missing, or filled teeth at the baseline examination. We believe that this finding is associated with the moderately low caries incidence in these control group subjects. It seems that in these subjects the basic prevention with fluorides, and their health behavior in other respects, too, is already so effective that additional prevention is hard to achieve. Both the usefulness and the cost-effectiveness of xylitol, therefore, are likely to be best among subjects who are more caries-active.

The greater reduction in girls than in boys during the post-use years is similar to the result in the original study (9). The sex difference in that study was almost totally explained by more regular use of xylitol chewing gum by the girls than by the boys. The long-term advantage found for the girls is in accordance both with the hypothesis of favorable bacterial colonization and also with that of proper maturation of the teeth.

The difference in total caries experience between the xylitol and control groups had further increased during the 2- or 3-yr follow-ups after the use of the preventive measure. In most cases the

\section{References}

1. Driscoll WS, Heifetz SB, Brunelle JA. Caries-preventive effects of fluoride tablets in schoolchildren four years after discontinuation of treatments. J Am Dent Assoc 1981; 103: 878-81.

2. Haugejorden O, Rise J. Caries prevalence in Norwegian recruits 5-7 years after discontinuation of supervised fluoride toothbrushing programmes. Caries Res 1981; 15: 308-17.

3. Ripa L, Leske G, Sposato A. A post-treatment benefit from a school-based F mouthrinsing program: results after up to 5 years of rinsing. J Dent Res 1982; 61: 280.

4. Haugejorden O, Lervik T, Riordan PJ. Comparison of caries prevalence 7 years after discontinuation of schoolbased fluoride rinsing or toothbrushing in Norway. Community Dent Oral Epidemiol 1985; 13: 2-6.

5. Alanen P, Tiekso J, Paunio I. Effect of war-time dietary changes on dental health of Finns 
post-experimental reduction percentage was actually greater, indicating an increasing difference also in caries incidence. This result was achieved at practically no new costs. For this reason, in the evaluation of cost-effectiveness the longterm effect should also be taken into account.

The present results suggest that caries prevention studies should not be terminated at the end of the active use of the treatment, since the total value of the method used can only be seen in the long run. The optimal timing and duration of caries prevention cannot be planned without knowledge of the long-term effects of the preventive procedure chosen, nor without knowledge of the association between the eruption of teeth and their long-term protection. If the hypotheses of favorable bacterial colonization and/ or successful maturation hold true, at least part of the preventive measures should be concentrated around the time of tooth eruption, rather than being applied evenly throughout a person's entire life.
40 years later. Community Dent Oral Epidemiol 1985; 13: 281-4.

6. Zickert I, EMILSON CG, Krasse B. Microbial conditions and caries increment 2 years after discontinuation of controlled antimicrobial measures in Swedish teenagers. Community Dent Oral Epidemiol 1987; 15: 241-4.

7. Ripa LW, Leske GS, VARMa AO. Longitudinal study of the caries susceptibility of occlusal and proximal surfaces of first permanent molars. J Publ Health Dent 1988; 48: 8-13.

8. KLOCK B. Economic aspects of a caries preventive program. Community Dent Oral Epidemiol 1980; 8: 97-102.

9. IsOKangas P. Xylitol chewing gum in caries prevention. A longitudinal study on Finnish school children. Proc Finn Dent Soc 1987; 83: Suppl I.

10. Isokangas P, Alanen P, TiEKSO J, MäKINEN KK. Xylitol chewing gum in caries prevention: a field study in children. J Am Dent Assoc 1988; 117: 315-20.

11. Scheinin A, MäKInEn KK, eds. Turku sugar studies I-XXI. Acta Odontol Scand 1975; 33 (suppl 70): 1-351.

12. SChernin A, BÁNóczy J, SzöKe J, et al. Collaborative WHO xylitol field studies in Hungary. I. Three-year caries activity in institutionalized children. Acta Odontol Scand 1985; 43: $327-47$.

13. Scheinin A, Pienihäkninen K, Tiekso J, et al. Collaborative WHO xylitol field studies in Hungary. VII. Two-year caries incidence in 976 institutionalized children. Acta Odontol Scand 1985; 43: 381-7.

14. Kandelman D, Gagnon G. Clinical results after 12 months from a study of the incidence and progression of dental caries in relation to consumption of chewing-gum containing xylitol in school preventive programs. J Dent Res 1987; 66: 1407-11.

15. Kandelman D, Bär A, HeFti A. Collaborative WHO xylitol field study in French Polynesia. I. Baseline prevalence and 32-month caries increment. Caries Res 1988; 22: 55-62.

16. MÄKINEN KK, IsOKANGAS P. Relationship between carbohydrate sweeteners and oral diseases. Prog Food Nutr Sci 1988; 12: 73-109.

17. Mäkinen KK, Söderling E, Isokangas P, Tenovuo J, Tiekso J. Oral biochemical status and depression of Streptococcus mutans in children during 24-36-month use of xylitol chewing gum. Caries Res: in press.

18. WHO: A guide to oral health epidemiological investigations: Geneva, 1979.

19. Carlos JP, GitTelsohn AM. Longitudinal studies of the natural history of caries. II. A life-table study of caries incidence in the permanent teeth. Arch Oral Biol 1965; 10: 739-51. 
This document is a scanned copy of a printed document. No warranty is given about the accuracy of the copy. Users should refer to the original published version of the material. 